\title{
Analgesic use among nursing homes residents, with and without dementia, in Poland
}

This article was published in the following Dove Press journal:

Clinical Interventions in Aging

21 March 2016

Number of times this article has been viewed

\author{
Agnieszka Neumann- \\ Podczaska' \\ Tomasz Nowak ${ }^{2}$ \\ Aleksandra Suwalska ${ }^{3}$ \\ Dorota Łojko 4 \\ Roma Krzymińska- \\ Siemaszko ${ }^{2}$ \\ Elżbieta Kozak-Szkopek ${ }^{5}$ \\ Katarzyna Wieczorowska- \\ Tobis $^{2}$ \\ 'Department of Geriatrics and \\ Gerontology, ${ }^{2}$ Department of \\ Palliative Medicine, Laboratory of \\ Geriatrics, ${ }^{3}$ Department of Psychiatry, \\ Laboratory of Neuropsychobiology, \\ ${ }^{4}$ Department of Adult Psychiatry, \\ Poznan University of Medical Sciences, \\ Poznan, ${ }^{5}$ Department of Geriatrics, \\ Medical University of Warsaw, \\ Warsaw, Poland
}

\begin{abstract}
Many age-associated diseases are accompanied by pain. There is no doubt that pain is underrecognized among elderly nursing home residents and the diagnosing of pain is a real challenge in subjects with dementia. The aim of the study was to characterize analgesic use among nursing home residents and to delineate the putative associations between pain management and cognitive functions of elderly persons. The study involved 392 subjects

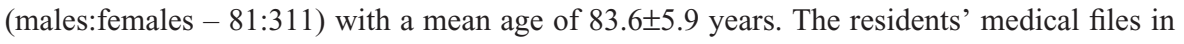
relation to diagnoses and drug consumption were analyzed, and the screening of cognitive functions was performed using the Mini-Mental State Examination (MMSE). One hundred and thirteen residents (28.8\%) received some analgesics. Among them 84 (21.4\%) used them routinely, $25(6.4 \%)$ - pro re nata (PRN) and four (1.0\%) - both routinely and PRN. Non-opioid analgesics were taken routinely by 53 residents, weak opioids by nine subjects, and one person was receiving strong opioids. Additionally, three individuals were taking a combination preparation of tramadol and acetaminophen. The rate of subjects who were not receiving any pain treatment was higher in residents with MMSE between 0 and 9 points than in those with MMSE between 24 and 30 points $(P=0.0151)$. Furthermore, ten residents $(9.1 \%)$ with severe dementia were treated with analgesics PRN. The results of our study point to a remarkably low use of analgesics in nursing home residents in Poland and indicate a need to introduce pain evaluation and monitoring of drug treatment appropriateness as a standard procedure in the geriatric assessment in nursing homes.
\end{abstract}

Keywords: pain, the elderly, analgesics, dementia, Mini-Mental State Examination, multimorbidity

\section{Introduction}

Multimorbidity defined as the co-occurrence of multiple chronic or acute diseases and medical conditions within one person is highly prevalent in the elderly. ${ }^{1}$ Many of the age-associated diseases are conditions that predispose to pain. However, age-banded data regarding the prevalence of pain are inconsistent. Data have been published showing that the rates of pain increase, ${ }^{2}$ do not change, ${ }^{3}$ or even decrease ${ }^{4}$ with age. Elderly subjects and their caregivers often believe that pain is a feature of normal aging and therefore they do not report it. ${ }^{5}$

There is no doubt that pain is underrecognized among elderly nursing home

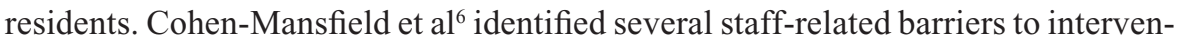
tion for pain in nursing homes. The most frequent staff-related barrier (concerning $24 \%$ of residents) was the physician concluding that the patient had no pain despite the detection of pain through formal assessment or observation. Underrecognition of pain is very common even in nursing home residents with cancer. Just recently, Pimentel et $\mathrm{al}^{7}$ showed that daily pain was present in two-thirds of nursing home
Correspondence: Aleksandra Suwalska Department of Adult Psychiatry, Laboratory of Neuropsychobiology, Poznan University of Medical Sciences, ul. Szpitalna 27/33, 60-572 Poznan, Poland Email suwalska_a@wp.pl (c) (1) (2) $\odot 2016$ Neumann-Podczaska et al. This work is published and licensed by Dove Medical Press Limited. The full terms of this license are available at https://www.dovepress.com/terms.php BV NC and incorporate the Creative Commons Attribution - Non Commercial (unported, v3.0) License (http://creativecommons.org/licenses/by-nd / $3.0 /$ ). By accessing the work you
hereby accept the Terms. Non-commercial uses of the work are permitted without any further permission from Dove Medical Press Limited, provided the work is properly attributed. For permission for commercial use of this work, please see paragraphs 4.2 and 5 of our Terms (https://www.dovepress.com/terms.php). 
residents with cancer in the USA and almost one in every five of them received no analgesics. The frequency of pain in European long-term care facilities varied between $32 \%$ and $57 \%$; in all countries cognitive impairment was correlated with less frequency of pain ${ }^{8}$ and less frequency of pain treatment. ${ }^{9}$

The detection of pain is a real challenge in subjects with dementia partly due to atypical presentation of pain in this group. These patients often are not able to communicate verbally, and thus pain might be expressed mainly via behavioral changes and/or psychiatric symptoms. It has been found that socially inappropriate behaviors, abnormal thought processes, and delusions are more common in nursing home residents with cognitive impairment, in whom pain was present ${ }^{10}$ than in those without pain. Clinicians may misinterpret these symptoms and fail to proceed with further pain-diagnosing and prescribe analgesics. ${ }^{9}$ There is evidence showing that pain treatment in nursing home residents with moderate-to-severe dementia significantly increases independent daily living activities ${ }^{11}$ and decreases the frequency of behavioral problems. ${ }^{12}$ The behavioral and psychological symptoms of dementia (such as agitation, aberrant motor behavior, anxiety, elation, irritability, depression, apathy, disinhibition, delusions, hallucinations, and sleep or appetite changes) affect up to $90 \%$ of all dementia subjects over the course of their illness ${ }^{13}$ and pain may strongly contribute to the occurrence and persistence of these symptoms. ${ }^{12}$

The aim of the study was to assess analgesic use among nursing home residents and to delineate the putative associations between pain management and cognitive functions of elderly persons. To the best of our knowledge, this is the first study to assess pain management in nursing home residents in Poland.

\section{Materials and methods}

\section{Participants}

Three hundred and ninety-two nursing home residents aged 75 years and above were included in the study. The subjects (or their representatives) gave their consent after receiving a full explanation of the nature of the study.

\section{Study procedure}

The project was approved by the National Committee for Scientific Research. The residents' medical files related to diagnoses and drug prescriptions were analyzed by the external researcher. Subsequently, the screening of cognitive functions was performed using the Mini-Mental State Examination (MMSE).

\section{The analysis of residents' medical files}

In each resident, the diagnoses were analyzed and the potentially pain-related diagnoses were selected, including deep vein thrombosis, rheumatoid arthritis, osteoarthritis, back pain, and pressure ulcers. ${ }^{5,14}$

The quantitative analysis of pharmacotherapy included calculation of the number of drugs consumed by each individual. For the purpose of the qualitative analysis, all drugs used by the studied residents were coded based on the Anatomical Therapeutic Chemical classification system. ${ }^{15}$ Particular attention was paid to analgesic drugs, which were divided based on the analgesic ladder. Among subjects treated with nonsteroidal anti-inflammatory drugs (NSAIDs), screening for contraindications including stomatitis, bleeding disorders, congestive heart failure, kidney insufficiency, and hypertension was performed. ${ }^{16}$

Prevalence of analgesic use was analyzed in three categories: regular use, pro re nata $(\mathrm{PRN})$, and their combination. Coanalgesics taken by $6.4 \%$ participants were not included in the detailed analysis of pain treatment. Due to the heterogeneity of different classes of coanalgesics, some of them could have been prescribed due to different diagnoses, not necessarily for pain treatment. ${ }^{17}$

\section{Cognitive screening}

Cognitive functions were assessed with MMSE. ${ }^{18}$ The results were corrected for age and education. ${ }^{19}$ The MMSE is a screening test for cognitive impairment, assessing orientation, memory, language, attention, calculation, and ability to follow simple verbal and written commands. Although it is not a diagnostic tool for dementia as such, its results may suggest dementia. The maximum score is 30 , with lower scores representing poorer performance. A result of 24-30 points meant no dementia (group A), result of 20-23 points - mild dementia (group B), 10-19 points - moderate dementia (group C), and 0-9 points - severe dementia (group D).

\section{Statistical analysis}

To evaluate the normality of distribution of the variables, the Shapiro-Wilk test was applied. As most of the investigated variables were not normally distributed, nonparametric tests were employed. Between-group differences were assessed by Fisher's exact test due to small sample size. All results were expressed as mean \pm standard deviation, as well as medians. Statistical significance was set at $P<0.05$ for all analyses. 
Table I Characteristics of study group

\begin{tabular}{lll}
\hline Characteristic & $\begin{array}{l}\text { Mean } \pm \text { standard } \\
\text { deviation }\end{array}$ & $\begin{array}{l}\text { Median; } \\
\text { range }\end{array}$ \\
\hline Age (years) & $83.6 \pm 5.9$ & $83 ; 75-102$ \\
Length of institutionalization (months) & $64.4 \pm 64.4$ & $43 ; 1-303$ \\
Number of diagnoses & $2.5 \pm 1.3$ & $2 ; 0-6$ \\
Number of used drugs & $5.5 \pm 3.0$ & $5 ; 0-13$ \\
MMSE (points) & $15.4 \pm 9.3$ & $17 ; 0-30$ \\
\hline
\end{tabular}

Abbreviation: MMSE, Mini-Mental State Examination.

\section{Results}

The characteristics of the study group are presented in Table 1.

\section{Characteristics of pain treatment in nursing home residents}

One hundred and thirteen residents $(28.8 \%$ of all studied subjects) received analgesic treatment. Among them, 84 (21.4\% of all studied subjects) used them regularly, 25 (6.4\%) - PRN, and four $(1.0 \%)$ - both regularly and PRN.

\section{Routine pain treatment}

Non-opioid analgesics were taken regularly by 53 residents. Only two subjects were taking acetaminophen and 51 NSAIDs. Among subjects treated with NSAIDs, three were taking concomitantly two different NSAIDs (meloxicam and ketoprofen, diclofenac, and ketoprofen; and ibuprofen and naproxen). Among subjects regularly taking NSAIDs, 22 were diagnosed with hypertension $(33.3 \%$ of subjects treated with NSAIDs), 14 (21.2\%) with congestive heart failure, two $(3.0 \%)$ with esophageal reflux, and one $(1.5 \%)$ with kidney insufficiency.
In regular therapy, weak opioids were only represented by tramadol: nine subjects were treated with tramadol in monotherapy. Additionally, three individuals received a combination preparation of tramadol and acetaminophen (one therapeutic formula). One subject was routinely treated with morphine. Detailed qualitative characteristics of pain treatment regarding MMSE results are presented in Table 2. The number of subjects who were not receiving any pain treatment was higher among those with MMSE between 0 and 9 points than in those with MMSE between 24 and 30 points $(P=0.0151)$.

\section{PRN pain treatment}

Non-opioid analgesics were taken PRN by 16 individuals. Among them, five were taking acetaminophen and eleven were taking NSAIDs. Tramadol was taken PRN by one resident and in a combination preparation with acetaminophen by three residents. Four residents were prescribed both regular and PRN pain medications.

As per the subgroups based on the MMSE results, we found that PRN pain treatment was prescribed to four subjects in group A, three in group B, eight in group $C$, and ten in group D. The prevalence of PRN pain treatment did not differ between the groups.

\section{Discussion}

To the best of our knowledge, this is the first study to assess pain management in residents of nursing homes in Poland.

The prevalence of pain treatment in our study was very low. Only one out of three analyzed subjects received any analgesic drug and only one out of five received a routine scheduled treatment. Analgesic medication was routinely

Table 2 Characteristics of regular pain treatment with respect to the MMSE results - group A MMSE results 24-30 points, group B (20-23 points), group C (10-19 points), group D (0-9 points)

\begin{tabular}{|c|c|c|c|c|}
\hline Characteristic & $\begin{array}{l}\text { Group A } \\
\mathrm{n}=\mathbf{8 2}\end{array}$ & $\begin{array}{l}\text { Group B } \\
n=67\end{array}$ & $\begin{array}{l}\text { Group C } \\
n=144\end{array}$ & $\begin{array}{l}\text { Group D } \\
\mathrm{n}=99\end{array}$ \\
\hline MMSE (points) & $24-30$ & $20-23$ & $10-19$ & $0-9$ \\
\hline No analgesics prescribed & $62(75.6 \%)$ & $55(82.1 \%)$ & $\begin{array}{l}122(84.7 \%) \\
P=0.1097 \text { vs group } A\end{array}$ & $\begin{array}{l}89(89.9 \%) \\
P=0.0151 \text { vs group } A\end{array}$ \\
\hline \multicolumn{5}{|l|}{ Routine step I (non-opioid) } \\
\hline Acetaminophen & 0 & 0 & I (0.7\%) & $\mathrm{I}(\mathrm{I} .0 \%)$ \\
\hline NSAIDs & $16(19.5 \%)$ & $12(17.9 \%)$ & $\begin{array}{l}17(I 1.8 \%) \\
P=0.1808 \text { vs group } A\end{array}$ & $\begin{array}{l}6(6.1 \%) \\
P=0.0233 \text { vs group } A\end{array}$ \\
\hline $\begin{array}{l}\text { Routine step } 2 \text { - tramadol } \\
\text { (weak opioids) }\end{array}$ & $2(2.4 \%)$ & 0 & $4(2.8 \%)$ & $3(3.0 \%)$ \\
\hline $\begin{array}{l}\text { Routine step } 3 \text { - morphine } \\
\text { (strong opioid) }\end{array}$ & 0 & 0 & 0 & I (I.0\%) \\
\hline $\begin{array}{l}\text { Acetaminophen }+ \text { tramadol } \\
\text { (one therapeutic formula) }\end{array}$ & $2(2.4 \%)$ & 0 & I (0.7\%) & 0 \\
\hline
\end{tabular}

Abbreviations: MMSE, Mini-Mental State Examination; NSAIDs, nonsteroidal anti-inflammatory drugs. 
received by one out of four subjects without dementia and only one out of ten with severe dementia. These numbers are much lower compared with data from other countries, where the prevalence of pain treatment with at least one analgesic ranges between $38.8 \%$ and $79.6 \%$ in subjects with no dementia and between $20.2 \%$ and $61.2 \%$ in those with dementia. ${ }^{17,20,21}$

These differences do not remain fully elucidated. They may be attributed to the heterogeneity of nursing home residents and care management, which is associated with the detection of pain. Nevertheless, in spite of the differences in prevalence of the use of analgesics, a common phenomenon is observed: residents with dementia are less likely to be treated with analgesic drugs than nondemented ones. While pain perception and processing are not diminished in dementia, patients' ability to express pain diminishes as they lose the ability to communicate pain verbally. ${ }^{22}$ Moreover, typical pain behaviors (behaviors indicating the presence of pain) also decrease with the progress of dementia. In elderly with severe dementia, an atypical presentation of pain occurs (eg, body movement, changes in behavior), which may be underrecognized, leading to inappropriate pain treatment. In these patients, neuroleptics are used to control pain-related behavioral and psychological symptoms.

In our study, while the prevalence of analgesic use in residents with moderate and severe dementia was relatively low, they were more likely to take neuroleptics than subjects without or with mild symptoms of dementia.

In our study, almost one out of ten subjects with severe dementia was given analgesics PRN. It must be underlined that although PRN pain treatment is believed to be adequate in cognitively intact residents, in those with moderate or severe dementia, who cannot advocate for themselves, such therapeutic approach is inappropriate and scheduled medications are recommended. ${ }^{23}$

According to current recommendations, acetaminophen is the first-line treatment in chronic pain management in elderly subjects. ${ }^{24}$ However, in our analysis, only two $(2.4 \%$ of those regularly treated with any analgesic) were treated with acetaminophen in monotherapy. Low use of acetaminophen has also been shown by Kölzsch et al, ${ }^{25}$ who studied nursing home residents in Germany. They have suggested that this may be due to the lack of reimbursement of acetaminophen in outpatient care in Germany. Also in Poland, the drug reimbursement system does not cover acetaminophen. However, insufficient knowledge of the long-term safety and efficacy of acetaminophen should also be taken into consideration. ${ }^{26}$ It is in agreement with another observation regarding high consumption of NSAIDs in our study. Based on the guidelines, these drugs should be used only for a short time, even in subjects with no contraindications. ${ }^{27}$ In our study, several residents were taking two NSAIDs at a time. There is no rationale behind duplicating any substances from the same therapeutic class as the risk of side effects significantly increases with no positive influence on the therapeutic effect. A high frequency of duplicate treatment with drugs from the same therapeutic class has also been shown for other drugs. ${ }^{27,28}$ Additionally, we also found subjects taking NSAIDs regardless of contraindications, most commonly represented by hypertension. It is well known that NSAIDs may both induce and exacerbate hypertension and thus result in the "prescribing cascade". ${ }^{29}$ Moreover, it has been shown that hypertension is a risk factor for cognitive impairment and thus it may lead to deterioration of functional independence. ${ }^{30}$

In our study, while the prevalence of analgesic use in residents with moderate and severe dementia was relatively low, they were more likely to take neuroleptics than subjects without dementia or with mild dementia according to MMSE (data not shown). Pain is often undetected or misinterpreted in people with dementia in residential aged care facilities, particularly those with communication difficulties. ${ }^{31}$ It causes discomfort and distress and is frequently the underlying cause of behavioral symptoms, which can lead to inappropriate treatment with antipsychotic medications. ${ }^{32}$

The main limitation of our study was the lack of pain assessment. It must be pointed out that pain detection is not part of the routine assessment in nursing home residents in Poland. At the national level, there is no standardized protocol for collecting information on patients' needs in long-term care facilities. Since our study was only based on data obtained from the existing nursing files, pain assessment is missing. An analysis of analgesic use in nursing home residents without pain assessment has also been conducted by another group. ${ }^{33}$ Additionally, the limitations of MMSE must also be taken into account. But still, it was shown that other tests have even more limited evidence in detecting dementia compared with MMSE. ${ }^{34}$ Thus, apart from its limitations, MMSE is still the most frequently used brief instrument for the cognitive screening, ${ }^{35,36}$ hence, we decided to use it in our study.

\section{Conclusion}

Our paper demonstrated a significantly low use of analgesics in nursing home residents in Poland. Raising awareness regarding the consequences of underrecognition and undertreatment of pain among health professionals is therefore necessary. 
There is a need to introduce pain evaluation as a routine element of geriatric assessment in nursing homes.

\section{Acknowledgment}

This project was supported by funding from the National Committee for Scientific Research (Kraków, Poland - grant No N N404 520738 and N N405 674340).

\section{Disclosure}

The authors report no conflicts of interest in this work.

\section{References}

1. Bayliss EA, Edwards AE, Steiner JF, Main DS. Processes of care desired by elderly patients with multimorbidities. Fam Pract. 2008;25: 287-293.

2. Edwards RR, Fillingim RB, Ness TJ. Age-related differences in endogenous pain modulation: a comparison of diffuse noxious inhibitory controls in healthy older and younger adults. Pain. 2003;101:155-165.

3. Jakobsson U, Klevsgård R, Westergren A, Hallberg IR. Old people in pain: a comparative study. J Pain Syptom Manage. 2003;26:625-636.

4. Życzkowska J, Szczerbińska K, Jantzi MR, Hirdes JP. Pain among the oldest old in community and institutional settings. Pain. 2007;129: $167-176$.

5. van Herk R, Boerlage AA, van Dijk M, Baar FP, Tibboel D, de Wit R. Pain management in Dutch nursing homes leaves much to be desired. Pain Manag Nurs. 2009;10:32-39.

6. Cohen-Mansfield J, Thein K, Marx MS, Dakheel-Ali M. What are the barriers to performing nonpharmacological interventions for behavioral symptoms in the nursing home? J Am Med Dir Assoc. 2012;13: 400-405.

7. Pimentel CB, Briesacher BA, Gurwitz JH, Rosen AB, Pimentel MT, Lapane KL. Pain management in nursing home residents with cancer. $J$ Am Geriatr Soc. 2015;63:633-641.

8. Achterberg WP, Gambassi G, Finne-Soveri H, et al. Pain in European long-term care facilities: cross-national study in Finland, Italy and The Netherlands. Pain. 2010;148:70-74.

9. Tan EC, Jokanovic N, Koponen MP, Thomas D, Hilmer SN, Bell JS. Prevalence of analgesic use and pain in people with and without dementia or cognitive impairment in aged care facilities: a systematic review and meta-analysis. Curr Clin Pharmacol. 2015;10:194-203.

10. Tosato M, Lukas A, van der Roest HG, et al. Association of pain with behavioral and psychiatric symptoms among nursing home residents with cognitive impairment: results from the SHELTER study. Pain. 2012; 153:305-310.

11. Chibnall JT, Tait RC, Harman B, Luebbert RA. Effect of acetaminophen on behavior, well-being, and psychotropic medication use in nursing home residents with moderate-to-severe dementia. J Am Geriatr Soc. 2005;53:1921-1929.

12. Husebo BS, Ballard C, Sandvik R, Nilsen OB, Aarsland D. Efficacy of treating pain to reduce behavioural disturbances in residents of nursing homes with dementia: cluster randomised clinical trial. $B M J$. 2011;343:d4065.

13. Cerejeira J, Lagarto L, Mukaetova-Ladinska EB. Behavioral and psychological symptoms of dementia. Front Neurol. 2012;3:73.

14. Monroe TB, Dietrich MS, Cowan RL, Simmons SF. Pain reports and pain medication treatment in nursing home residents with and without dementia. Geriatr Gerontol Int. 2014;14:541-548.

15. WHO Collaborating Centre for Drug Statistics Methodology. Guidelines for ATC Classification and DDD Assignment 2013. Oslo: WHO Collaborating Centre for Drug Statistics Methodology; 2012.
16. McLachlan AJ, Bath S, Naganathan V, et al. Clinical pharmacology of analgesic medicines in older people: impact of frailty and cognitive impairment. Br J Clin Pharmacol. 2011;71:351-364.

17. de Souto Barreto P, Lapeyre-Mestre M, Vellas B, Rolland Y. Potential underuse of analgesics for recognized pain in nursing home residents with dementia: a cross-sectional study. Pain. 2013;154:2427-2431.

18. Folstein MF, Folstein SE, McHugh PR. "Mini-mental state". A practical method for grading the cognitive state of patients for the clinician. J Psychiatr Res. 1975;12:189-198.

19. Mungas D, Marshall SC, Weldon M, Haan M, Reed BR. Age and education correction of Mini-Mental State Examination for English and Spanish-speaking elderly. Neurology. 1996;46:700-706.

20. Nygaard HA, Jarland M. Are nursing home patients with dementia diagnosis at increased risk for inadequate pain treatment? Int J Geriatr Psychiatry. 2005;20:730-737.

21. Reynolds KS, Hanson LC, DeVellis RF, Henderson M, Steinhauser KE. Disparities in pain management between cognitively intact and cognitively impaired nursing home residents. J Pain Symptom Manage. 2008; 35:388-396.

22. Cole LJ, Farrell MJ, Duff EP, Barber JB, Egan GF, Gibson SJ. Pain sensitivity and fMRI pain related brain activity in Alzheimer's disease. Brain. 2006;129:2957-2965.

23. Haasum Y, Fastbom J, Fratiglioni L, Kåreholt I, Johnell K. Pain treatment in elderly persons with and without dementia: a population-based study of institutionalized and home-dwelling elderly. Drugs Aging. 2011; 28:283-293.

24. American Geriatrics Society Panel on the Pharmacological Management of Persistent Pain in Older Persons. Pharmacological management of persistent pain in older persons. Pain Med. 2009;10:1062-1083.

25. Kölzsch M, Wulff I, Ellert S, et al. Deficits in pain treatment in nursing homes in Germany: a cross-sectional study. Eur J Pain. 2012;16: 439-446.

26. Reid MC, Bennett DA, Chen WG, et al. Improving the pharmacologic management of pain in older adults: identifying the research gaps and methods to address them. Pain Med. 2011;12:1336-1357.

27. Clinard F, Sgro C, Bardou M, et al. Association between concomitant use of several systemic NSAIDs and an excess risk of adverse drug reaction. A case/non-case study from the French Pharmacovigilance system database. Eur J Clin Pharmacol. 2004;60:279-283.

28. Rajska-Neumann A, Wieczorowska-Tobis K, Schulz M, Breborowicz A, Grzeskowiak E, Oreopoulos DG. Duplicate use of angiotensin-converting enzyme (ACE) inhibitors in a community-dwelling elderly population in Poland. Arch Gerontol Geriatr. 2007;44(Suppl 1):295-301.

29. Rochon PA, Gurwitz JH. Optimising drug treatment for elderly people: the prescribing cascade. BMJ. 1997;315:1096-1099.

30. Łojko D, Wegner A, Czajkowska A, et al. Factors contributing to cognitive deficits in elderly residents of rural areas. Eur Rev Med Pharmacol Sci. 2015;19:2590-2596.

31. Peisah C, Weaver J, Wong L, Strukovski JA. Silent and suffering: a pilot study exploring gaps between theory and practice in pain management for people with severe dementia in residential aged care facilities. Clin Interv Aging. 2014;9:1767-1774.

32. Achterberg WP, Pieper MJ, van Dalen-Kok AH, et al. Pain management in patients with dementia. Clin Interv Aging. 2013;8:1471-1482.

33. Nygaard HA, Naik M, Ruths S, Straand J. Nursing-home residents and their drug use: a comparison between mentally intact and mentally impaired residents. The Bergen district nursing home (BEDNURS) study. Eur J Clin Pharmacol. 2003;59:463-469.

34. Lin JS, O'Connor E, Rossom RC, Perdue LA, Eckstrom E. Screening for cognitive impairment in older adults: a systematic review for the U.S. Preventive Services Task Force. Ann Intern Med. 2013;159:601-612.

35. Ismail Z, Rajji TK, Shulman KI. Brief cognitive screening instruments: an update. Int J Geriatr Psychiatry. 2010;25:111-120.

36. Mitchell AJ. A meta-analysis of the accuracy of the mini-mental state examination in the detection of dementia and mild cognitive impairment. J Psychiatr Res. 2009;43:411-431. 


\section{Publish your work in this journal}

Clinical Interventions in Aging is an international, peer-reviewed journal focusing on evidence-based reports on the value or lack thereof of treatments intended to prevent or delay the onset of maladaptive correlates of aging in human beings. This journal is indexed on PubMed Central, MedLine,

CAS, Scopus and the Elsevier Bibliographic databases. The manuscript management system is completely online and includes a very quick and fair peer-review system, which is all easy to use. Visit http://www.dovepress. com/testimonials.php to read real quotes from published authors. 